\title{
Assessing and Exploring the Competency of Prehospital Emergency Medical Service Personnel in Klang Valley, Malaysia: a Mixed Method Approach
}

\author{
Mohd Said $\mathrm{N}^{\mathrm{a}}$, Sukonthasarn $\mathrm{A}^{\mathrm{b}}$, Wangsrikhun $\mathrm{S}^{\mathrm{b}}$, Chanpransit $\mathrm{C}^{\mathrm{c}}$ \\ aDepartment of Critical Care Nursing, Kulliyyah of Nursing, International Islamic University Malaysia \\ ${ }^{b}$ Department of Surgical Nursing, Faculty of Nursing, Chiang Mai University \\ 'Department of Public Health Nursing, Faculty of Nursing, Chiang Mai University
}

\begin{abstract}
Introduction: The notion of competency in pre-hospital emergency medical service (EMS) personnel is mainly focused on the professional proficiency that he/she has to provide intervention outside of hospital setting. Consequently, the effectiveness of pre-hospital EMS performance very much depends upon the capability of the personnel at the scene and as well during transport to the definitive care center. The aim of this study is to appraise and explore the competency of pre-hospital care staff and provide strategies for improvement. Methods: A mixed method approach combining the qualitative and quantitative study design. Of 134 staffs only $111(82.84 \%)$ returned the questionnaire. Nine semi-structured interviews and two focus group discussions were performed. The main informants were nurses/assistant medical officers, nurse/assistant medical officer administrators, and emergency physicians. Results: From the quantitative finding on the competency of staff handling pre-hospital EMS, all had the essential knowledge and skills. However, most of them reported not having good knowledge and skills for invasive procedures (31\%-61\%), include giving medications (61\%-66\%). The qualitative information provided insight about the issues and strategies for the personnel in regards to competency. All the relevant qualitative data were merged into 5 categories relating issues and 5 categories to strategies that could affect the competency of the personnel. Conclusion: Pre-hospital EMS systems need to consider that the competency of pre-hospital EMS personnel has to come along with the responsible attitude of the staff itself, the support of medical direction, clear protocol for guiding them whenever needed, and continuous professional-development courses require them to maintain their professional proficiency.
\end{abstract}

KEYWORDS: Emergency medical service, competency, nurse and assistant medical officer, mixed method research

\section{INTRODUCTION}

The competency of pre-hospital emergency medical service (EMS) personnel is mainly focused on the professional proficiency that he/she has to provide intervention out of the hospital context. Thus the effectiveness of pre-hospital EMS performance relies very much on the competency of the personnel to provide the care at the scene, and during transport to the definitive care center. This is because the quality of any health care system is largely determined by the

Correspondence author:

Mohd Said Nurumal

Dept. of Critical Care Nursing

Kulliyyah of Nursing

International Islamic University Malaysia

Level 2, Jalan Hospital Campus

P.O Box 141, 25710 Kuantan

Pahang Darul Makmur

Tel. No.: +609-513 3710 (office)

$+6013-3853850$ (mobile)

Fax No.: +609-513 3615

Email.: mohdsaid@iium.edu.my mohdsaidnurumal@gmail.com knowledge, skills and attitudes of its personnel. ${ }^{1}$ Most pre-hospital EMS systems worldwide are composed of providers with one or more levels of training and skills. For instance, the first tier is basic life support, also known as first responder. This is followed by the second tier, an emergency medical technician, and then a third tier known as advanced life support or paramedic or emergency nurse. Each of these personnel levels has its credentials recognised by the state, namely basic, intermediate and advanced certification. ${ }^{1}$

Currently in Malaysia only one tier of health care provision is available for pre-hospital care at an advanced life support level. They are the registered nurses (RNs) or assistant medical officers (AMOs). In Malaysia the health care providers for both outside and inside the hospital are the same. These personnel are generally skilled for in-hospital care and little emphasis is given to pre-hospital care in their programs. In addition, pre-hospital care personnel in Malaysia can receive support through medical direction, following guidelines or protocol and by completing a refresher course aimed at improving their 
competency. Malaysia also has first responders to assist at the basic life support level. They normally operate when there are disasters or mass-casualty incidents, and are assisted by public civil-defense volunteers and some non-government organizations such as the Red Crescent ambulances. When the Medical Emergency Coordination Center (MECC) has determined that the situation is not life-threatening, then basic lifesupport staff will be dispatched.

The demand for pre-hospital EMS around the world has greatly increased because nowadays the public often faces both serious medical illnesses and the risk of injuries. Effective pre-hospital care is achieved when the timely delivery of care can limit the sequence of events that can otherwise quickly lead to death or lifelong disability. ${ }^{2,3,4,5}$ Many pre-hospital deaths can be prevented if the victim receives immediate and appropriate care. Thus health-care delivery system in most countries, including Malaysia, provide this prehospital EMS system as a formal service. This is provided as the first point of contact for those who require health-care services during life-threatening situations. It also act as a gate-keeping step for accessing immediate care for reducing death and disability. ${ }^{6,7,8,9}$

Pre-hospital care service is required if the healthcare provider of pre-hospital care is operating at peak efficiency. Maintaining care at a high standard is crucial because it can prevent death, reduced complications or suffering and improve patient outcomes. ${ }^{7,10,11,12,13,14,15}$ A classic report by the National Academy of Sciences -National Research Council, ${ }^{16}$ entitled "Accidental Death and Disability: The Neglected Disease of Modern Society", has summarized practices and deficiencies in pre-hospital EMS. Many countries have followed suggestions by the National Research Council, mainly in the training of personnel, to implement best practices in pre-hospital care. Medical direction by an emergency physician is an essential component of modern EMS. ${ }^{17}$ Moreover, EMS systems require participation by a knowledgeable physician and supervision at every level, at the scene and/or during transport. ${ }^{18}$

Bigham and colleagues ${ }^{19}$ conducted a qualitative study to identify the barriers facing personnel while making decisions at the scene, which sometimes delay prehospital care. In the past little was known about the implementation of scientific evidence, especially relating to the American Heart Association guidelines, in pre-hospital care practice. Delays in instruction/ training were the most commonly reported themes reported by participating services. Delays were broken down into three major categories. The first was delay finding certified instructors to lead the training. Next was the delay in receiving the printed training material required for instruction. The third was delay in scheduling continuing medical education sessions. Thus comprehensive professional development education for pre-hospital personnel has been established as necessary for improving patient outcomes. This has been demonstrated by several studies that have examined these matters and shown their effectiveness. ${ }^{12,20,21}$ Surprisingly, pre-hospital care providers also face dilemmas which can lead to inadequate performance when relatives refuse care, or there is conflict among relatives and their significant others. ${ }^{22}$

The competency of pre-hospital EMS personnel can be defined in terms of the quality of the out-of-hospital care provided. This is the care given by RN/AMOs of the MECC in providing pre-hospital care to a victim who has a medical-emergency or life-threatening condition. The service begins from the time a call is received at the dispatch center and the arrival of the by ambulance at the definitive trauma and emergency department of the hospital. The aim of the research reported in this paper was to assess and explore the competency of pre-hospital care personnel, and to recommend strategies for improvement. This article only deals with one of several indicators of prehospital EMS performance components. It is part of a larger study that covers the structure, process and outcome guided by the quality of care featured in the Donabedian ${ }^{23}$ model and underpinning pragmatic philosophy. ${ }^{24}$

\section{MATERIALS AND METHODS}

This is a descriptive study utilizing a mixed-method approach. In this study the method using qualitative data was embedded in quantitative data. By using a study design with two different methods a researcher can gain perspectives from the different levels of EMS personnel. Thus in this study qualitative methods are able to explain the phenomenon in a real setting towards the quantitative methods. ${ }^{25,26}$

The study was conducted at two out of seven Klang Valley MECCs, Kuala Lumpur and Sungai Buloh. The biggest MECC is Kuala Lumpur, a central control for the 3 tertiary hospitals and 3 ambulance service centers. They receive approximately 150 calls a day and 3000 calls a month. For the year 2011 HKL MECC received 34041 calls and dispatched 28631 calls, and the HSB MECC received 3473 calls and dispatched 2551 calls. Thus for this study the researcher selected the biggest MECC center and Sungai Buloh's MECC as one of the single function centers which covers the suburbs area. The reason for choosing biggest center was because it has more cases and a single center was used mainly to compare any differences or similarities in pre-hospital performance. The duration of the study was from February 2013 to April 2013. The researcher recruited all the RNs and AMOs in the Kuala Lumpur and Sungai Buloh's MECCs who fulfilled the inclusion criteria which were RN/AMOs who work in in emergency and trauma departments, and have more than one-year of experience in dealing with pre-hospital care (RN/AMOs in administration positions in pre-hospital care service were excluded). As for the qualitative study, purposive sampling techniques were used for the selection of informants. The key informants consisted of the national head of the emergency physicians, emergency physicians, the head nurse/assistant medical 
officer and RN/AMOs. The inclusion criteria for the key informants was being able to express their personal thoughts and opinions regarding pre-hospital care provided by RN/AMOs. This research was approved by the Research and Ethic Committee at Chiang Mai University, the Clinical Research Center for both MECCs and the National Medical Research Register.

The quantitative research instrument used was the Essential Knowledge and Skills Questionnaire (EKSQ). This is a structured, guided, self-administrated questionnaire, developed by the $\mathrm{WHO}^{1}$; the form was modified by the researcher in accord with the cultural context. There are five main subscales: a) alert; b) scene survey; c) provider safety; d) patient assessment; and e) intervention. All measure the prehospital care competency for the health care provider through a total of 58 items. The ESKQ was took the form of dichotomous options (Yes or No) in two columns for knowledge and skill. In addition, demographic data were collected in the same instrument, employing a data form developed by the researcher. Demographic data included age, gender, educational level, working experience, and professional development programs undertaken.

These programs related to pre-hospital care and any credential certificates, such Basic Life Support (BLS), Advanced Life Support (ALS) and Trauma courses. The instrument was set out in the English language. There were four components of instruments used in the qualitative approach, namely: the researcher himself; semi-structured interviews and focus group discussion guidelines; tape recording of interviews; and a diary of the study.

All the data were collected by the researcher himself, assisted by technical staff whenever necessary. Respondents were given a cover letter and consent form and their signatures were required before they answered the questionnaire and interview session. Prior to recording material, the researcher sought permission from the participants and explained that the purpose of the recording was to transcribe conversations for analysis. The interviews were not longer than an hour, unless the participant wished to share more. Interviews and discussions were conducted in the preferred language of the participant, that is Malay, English or using both (refer Figure 1 for data collection procedure).

Prior to the distribution of the ESKQs, the content was tested by five experts in pre-hospital care discipline using a Content Validity Index and the score is 1.00 out of 1.00 . The reliability of the test-retest of 15 respondents after a period of two weeks was .825, and the Cronbach's Alpha of this EKSQ was .862. The trustworthiness of the data was maintained by following the tenets established by Lincoln and Guba. ${ }^{27}$ The credibility was affirmed through memberchecking with five participants for the transcribing of the verbatim, open coding and categories. Rich descriptions were undertaken to increase the potential transferability of the findings to other settings and situations. To establish dependability, the preliminary categories were compared and discussed within teams in this study. The raw data, reflexive journals, field notes, memos, and products of the data analysis used enhanced the trustworthiness and confirmability of the data.

The data was analyzed using both quantitative and qualitative techniques. The quantitative data were computed using the SPSS version $\mathbf{2 1 . 0}$ for the analysis of descriptive statistics. The researcher analysed the qualitative data using his own standards, closely guided by the research team. For quality data-management and analysis, the researcher followed the Graneheim and Lundman ${ }^{28}$ content-analysis approach, including the techniques of 'coding', and identifying emerging 'categories',

\section{RESULTS}

Table I provides data from the quantitative study; 111 out of $134(82.84 \%)$ staff returned the questionnaire from both MECCs. In this study a total of 83 out of 111 were nurses and 65 of those were from the HKL MECC; the rest were from the HSB MECC. Nearly $70 \%$ of these study-group subjects were female and most are diploma-holders. Only 35 staff held a post basic qualification in emergency and trauma care, and 8 had upgraded to Bachelor of Nursing studies. All of them were certified in basic life support and trauma care. However, there were still some staff waiting for a renewal of their certificate for advanced life support. The mean ages of the HKL and HSB MECC respondents were 29.61 (SD 4.99) and 28.84 (SD 3.86) respectively. These two groups of respondents from the MECCs were not much different in terms of years of experience, as the EMS staff record of the HSB MECC was 5.13 (SD 2.72) and the HKL MECC was 4.89 (SD 3.11).

In the qualitative study (see Table II), the various levels of health-care personnel participated in focus-group discussions and semi-structured interviews. The staff consisted of many levels, from lower rank to higher level administration officers. They were mainly nurses, assistant medical officers and emergency physicians; some held superior positions in their professions. Of the 22 participants, 13 of the two groups took part in focusgroup discussions, and the rest were key informants who took part in semi-structured interviews. Most were recruited in the Klang Valley area and had great experience in dealing with the EMS. The focus group discussions and interviews were continued until the data reached saturation point.

Table III provides an overview of the essential knowledge of and skills in pre-hospital care of the RN/ AMOs in both MECCs in the Klang Valley. Interestingly, both groups showed almost the same levels of knowledge of and skill in pre-hospital care; there is no great difference in term of percentage. 


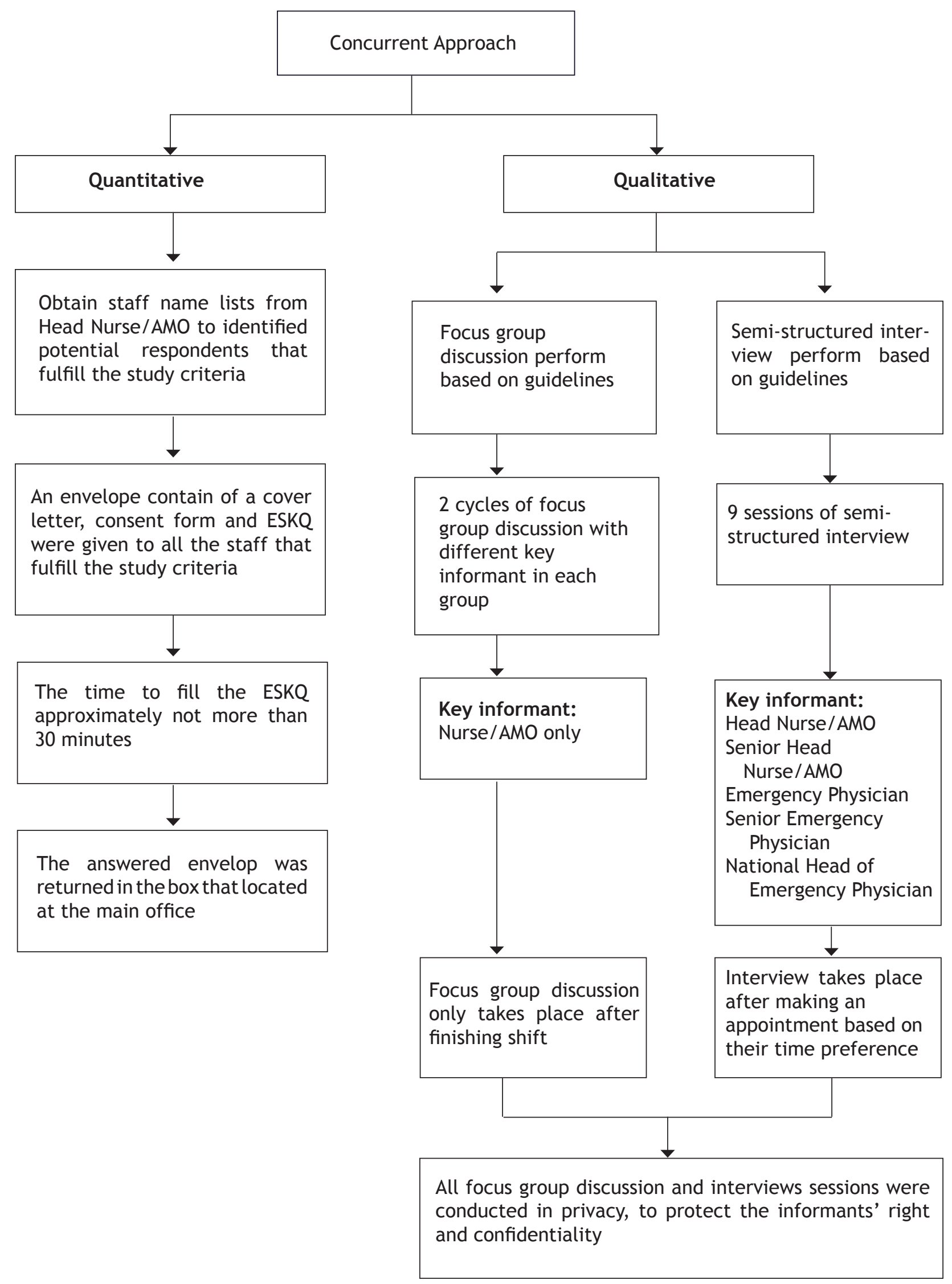

Figure 1. Data Collection Procedure Approach for both Methods 
Table I. Characteristic of Samples in Quantitative Study ( $\mathrm{n}=111)$

Characteristics

HKL MECC

HSB MECC
n (\%)
Mean (SD)
n (\%)
Mean (SD)

Staff

$80(72.1)$

$31(27.9)$

Nurse

$65(81.2)$

$18(58.1)$

AMO

$15(18.8)$

13 (41.9)

Gender
Male
$22(27.5)$
15 (58.4)
Female
58 (72.5)
$16(51.6)$

Education

$\begin{array}{lll}\text { Bach** }^{* *} & 7(8.8) & 1(3.3) \\ \text { Post Basic* } & 26(32.5) & 9(29.0) \\ \text { Diploma } & 47(58.7) & 21(67.7)\end{array}$

$\begin{array}{llll}\text { Certificate } & \text { BLS } & 80(100) & 31(100) \\ & \text { ALS*** } & 66(82.5) & 17(54.8) \\ & \text { Trauma } & 80(100) & 31(100)\end{array}$

Age

29.61(4.99)

28.84(3.86)

Range

Range

24-37

23-34

Years of

6.46(4.56)

5.61(3.41)

Experience

Range

Range

as a Staff

2.5-11

2-9

Years of

experience

4.89(3.11)

5.13(2.72)

Range

Range

as an EMS

1.5-9

2-7

Staff

* Post Basic is a 6 month course of Emergency \& Trauma Care after Diploma

** Bachelor is a 2 year course of Nursing Studies after Diploma and Post Basic

*** The remaining staff is waiting to renew their certificate 
Table II. Demographic Characteristic of participant in Qualitative Study ( $\mathrm{n}=22$ )

$\begin{array}{lll}\text { Characteristics } & \mathrm{n}(\%) & \text { Range }\end{array}$

Gender

Male

$9(40.9)$

Female

$13(59.1)$

Age

$24-56$

Years of Experience in Trauma \&

Emergency

Job Position

$\begin{array}{lc}\begin{array}{l}\text { National Head of Emergency } \\ \text { Physician }\end{array} & 1(4.5) \\ \text { Senior Emergency Physician } & 1(4.5) \\ \text { Emergency Physician } & 2(9.1) \\ \text { Senior Head Nurse } & 2(9.1) \\ \begin{array}{l}\text { Senior Head Assistant Medical } \\ \text { Officer }\end{array} & 1(4.5) \\ \text { Head Nurse } & 1(4.5) \\ \text { Head Assistant Medical Officer } & 1(4.5) \\ \text { Nurse } & 9(40.9) \\ \text { Assistant Medical Officer } & 4(18.2)\end{array}$


Table III. Knowledge and Skills of Pre-hospital Care Personnel for the Klang Valley, MECC. $\mathrm{n}=111,(\mathrm{RNs}=83$ and $\mathrm{AMOs}=28)$

\begin{tabular}{|c|c|c|c|c|}
\hline \multirow{2}{*}{$\begin{array}{r}\text { Subscales } \\
\text { Items }\end{array}$} & \multicolumn{2}{|c|}{ Knowledge $n(\%)$} & \multicolumn{2}{|c|}{ Skill n(\%) } \\
\hline & RN & AMO & $\mathrm{RN}$ & AMO \\
\hline \multicolumn{5}{|l|}{ Subscale 1: Alert } \\
\hline 1. Able to call for help around the scene & $83(100)$ & $28(100)$ & $82(99)$ & $27(96)$ \\
\hline $\begin{array}{l}\text { 2. Able to call medical director (emergency } \\
\text { physician) for help }\end{array}$ & $82(99)$ & $27(96)$ & $77(93)$ & $24(86)$ \\
\hline \multicolumn{5}{|l|}{ Subscale 2: Scene survey } \\
\hline $\begin{array}{l}\text { 3. Assess scene safety (physical and } \\
\text { environment hazard) }\end{array}$ & $82(99)$ & $28(100)$ & $81(98)$ & $27(96)$ \\
\hline 4. Assess cause of injury or disease severity & $82(99)$ & $28(100)$ & $81(98)$ & $27(96)$ \\
\hline \multicolumn{5}{|l|}{ Subscale 3: Provider safety } \\
\hline 5. Receive training in universal precaution & $81(98)$ & $28(100)$ & $81(98)$ & $27(96)$ \\
\hline \multicolumn{5}{|l|}{ Subscale 4: Patient assessment } \\
\hline 6. Evaluate adequacy of airway & $83(100)$ & $28(100)$ & $83(100)$ & $28(100)$ \\
\hline 7. Evaluate adequacy of breathing & $83(100)$ & $27(96)$ & $83(100)$ & $28(100)$ \\
\hline 8. Evaluate adequacy of circulation & $83(100)$ & $28(100)$ & $83(100)$ & $28(100)$ \\
\hline 9. Recognize level of consciousness & $82(99)$ & $28(100)$ & $82(99)$ & $28(100)$ \\
\hline 10. Recognize presence of life threatening & $82(99)$ & $28(100)$ & $83(100)$ & $28(100)$ \\
\hline $\begin{array}{l}\text { 11. Recognize when life threatening condition is } \\
\text { not survivable }\end{array}$ & $80(96)$ & $28(100)$ & $78(94)$ & $27(96)$ \\
\hline $\begin{array}{l}\text { 12. Establish priorities for immediate care } \\
\text { Detailed assessment }\end{array}$ & $83(100)$ & $28(100)$ & $83(100)$ & $27(96)$ \\
\hline 13. Assess head & $82(99)$ & $28(100)$ & $82(99)$ & $27(96)$ \\
\hline 14. Assess spinal & $80(96)$ & $28(100)$ & $78(94)$ & $28(100)$ \\
\hline 14. Assess spinal & $80(96)$ & $28(100)$ & $78(94)$ & $28(100)$ \\
\hline 15. Assess chest & $81(98)$ & $28(100)$ & $81(98)$ & $27(96)$ \\
\hline 16. Assess abdominal & $80(96)$ & $28(100)$ & $81(98)$ & $28(100)$ \\
\hline 17. Assess upper/ lower extremity & $81(98)$ & $28(100)$ & $82(99)$ & $28(100)$ \\
\hline
\end{tabular}


Table III (Cont.)

\begin{tabular}{|c|c|c|c|c|}
\hline \multirow{2}{*}{$\begin{array}{l}\text { Subscales } \\
\text { Items }\end{array}$} & \multicolumn{2}{|c|}{ Knowledge $n(\%)$} & \multicolumn{2}{|c|}{ Skill n(\%) } \\
\hline & $\mathrm{RN}$ & AMO & $\mathrm{RN}$ & AMO \\
\hline 18. Assess neurological function & $78(94)$ & $28(100)$ & $74(89)$ & $26(93)$ \\
\hline 19. Evaluate level of discomfort & $83(100)$ & $28(100)$ & $83(100)$ & $28(100)$ \\
\hline 20. Recognize hypothermia & $80(96)$ & $26(93)$ & $78(94)$ & $25(89)$ \\
\hline 21. Assess evidence of shock & 79(95) & $27(96)$ & $75(90)$ & $26(93)$ \\
\hline $\begin{array}{l}\text { 22. Assess degree of burn (depth and } \\
\text { extent) }\end{array}$ & $75(90)$ & $26(93)$ & $69(83)$ & $24(86)$ \\
\hline \multicolumn{5}{|l|}{ Subscale 5: Intervention } \\
\hline 23. Remove foreign body from airway & $80(96)$ & $27(96)$ & $79(95)$ & $25(89)$ \\
\hline $\begin{array}{l}\text { 24. Restore open airway using manual } \\
\text { maneuvers e.g head tilt-chin lift }\end{array}$ & $80(96)$ & $28(100)$ & $81(98)$ & $27(96)$ \\
\hline $\begin{array}{l}\text { 25. Restore open airway using recovery } \\
\text { position }\end{array}$ & $82(99)$ & $28(100)$ & $82(99)$ & $28(100)$ \\
\hline $\begin{array}{l}\text { 26. Provide respiratory support use } \\
\text { pocket mask }\end{array}$ & $82(99)$ & $28(100)$ & $76(92)$ & $25(89)$ \\
\hline 27.Use suction devices & $82(99)$ & $28(100)$ & $82(99)$ & $27(96)$ \\
\hline 28. Insert airways & $82(99)$ & $27(96)$ & $81(98)$ & $27(96)$ \\
\hline $\begin{array}{l}\text { 29. Assist ventilation using bag-valve-mask- } \\
\text { device }\end{array}$ & $82(99)$ & $27(96)$ & $82(99)$ & $27(96)$ \\
\hline 30.Administer oxygen & $83(100)$ & $28(100)$ & $83(100)$ & $28(100)$ \\
\hline 31.Perform cricothyroidotomy & $55(66)$ & $23(82)$ & $33(40)$ & $17(61)$ \\
\hline \multicolumn{5}{|l|}{ Circulation, hypothermia and shock } \\
\hline 32. Control external hemorrhage & $80(96)$ & $26(93)$ & $78(94)$ & $26(93)$ \\
\hline $\begin{array}{l}\text { 33. Elevate patient's leg if there is evidence } \\
\text { of shock }\end{array}$ & $80(96)$ & $26(93)$ & $78(94)$ & $26(93)$ \\
\hline $\begin{array}{l}\text { 34. Immobilize the patient to ease pain, and } \\
\text { reduce bleeding }\end{array}$ & $83(100)$ & $28(100)$ & $82(99)$ & $28(100)$ \\
\hline $\begin{array}{l}\text { 35. Splint fracture for hemorrhage and pain } \\
\text { control }\end{array}$ & $81(98)$ & $28(100)$ & $78(94)$ & $28(100)$ \\
\hline 36. Prevent heat loss with blankets & $81(98)$ & $28(100)$ & $81(98)$ & $28(100)$ \\
\hline 37. Monitor body temperature & $83(100)$ & $28(100)$ & $83(100)$ & $28(100)$ \\
\hline 38.Monitor glucose level & $82(99)$ & $27(96)$ & $82(99)$ & $27(96)$ \\
\hline 39. Established intravenous access & $83(100)$ & $27(96)$ & $81(98)$ & $27(96)$ \\
\hline 40.Administer intravenous fluid replacement & $83(100)$ & $26(93)$ & $81(98)$ & $27(96)$ \\
\hline $\begin{array}{l}\text { 41. Established intraosseouss access for } \\
\text { children }\end{array}$ & $66(80)$ & $22(79)$ & $26(31)$ & $10(36)$ \\
\hline
\end{tabular}


Table III (Cont.)

\begin{tabular}{|c|c|c|c|c|}
\hline \multirow{2}{*}{$\begin{array}{l}\text { Subscales } \\
\text { Items }\end{array}$} & \multicolumn{2}{|c|}{ Knowledge $n(\%)$} & \multicolumn{2}{|c|}{ Skill n(\%) } \\
\hline & RN & AMO & RN & AMO \\
\hline \multicolumn{5}{|l|}{ Wounds and Burns } \\
\hline $\begin{array}{l}\text { 42. Nonsurgical management of wound } \\
\text { dressing }\end{array}$ & $81(98)$ & $27(96)$ & $82(99)$ & $28(100)$ \\
\hline 43. Cool the burn area with water & $82(99)$ & $27(96)$ & $80(96)$ & $27(96)$ \\
\hline 44. Cover the skin with sterile dressing & $81(98)$ & $28(100)$ & $81(98)$ & $28(100)$ \\
\hline \multicolumn{5}{|l|}{ Injuries extremities, head\&spinal } \\
\hline $\begin{array}{l}\text { 45. Use basic immobilization for fractured } \\
\text { extremities }\end{array}$ & $83(100)$ & $27(96)$ & $81(98)$ & $27(96)$ \\
\hline 46. Use available material for splint & $80(96)$ & $28(100)$ & $79(95)$ & $27(96)$ \\
\hline 47. Use head immobolizer & $82(99)$ & $28(100)$ & $81(98)$ & $28(100)$ \\
\hline 48. Use cervical collar & $83(100)$ & $27(96)$ & $82(99)$ & $27(96)$ \\
\hline 49. Use spine board & $83(100)$ & $28(100)$ & $82(99)$ & $28(100)$ \\
\hline $\begin{array}{l}\text { 50. Use spinal precaution when moving } \\
\text { patients }\end{array}$ & $81(98)$ & $27(96)$ & $81(98)$ & $27(96)$ \\
\hline \multicolumn{5}{|l|}{ Resuscitation } \\
\hline 51. Perform CPR & $83(100)$ & $28(100)$ & $83(100)$ & $28(100)$ \\
\hline 52. Perform ACLS & $59(71)$ & $24(86)$ & $55(66)$ & $18(64)$ \\
\hline 53. Perform Trauma Care & $60(72)$ & $25(89)$ & $57(69)$ & $24(86)$ \\
\hline 54. Apply AED & $81(98)$ & $28(100)$ & $83(100)$ & $28(100)$ \\
\hline \multicolumn{5}{|l|}{ Medicines (with medical direction) } \\
\hline $\begin{array}{l}\text { 55. Manage pain with non-narcotic } \\
\text { analgesic }\end{array}$ & $81(98)$ & $26(93)$ & $79(95)$ & $25(89)$ \\
\hline 56. Manage pain with narcotic analgesic & $73(88)$ & $24(86)$ & $73(88)$ & $21(75)$ \\
\hline $\begin{array}{l}\text { 57. Administer other medicine that } \\
\text { relevant to disease }\end{array}$ & $70(84)$ & $23(82)$ & $68(82)$ & $20(71)$ \\
\hline $\begin{array}{l}\text { 58. Administer medicine that requires } \\
\text { during CPR/ACLS/Trauma Care }\end{array}$ & $68(82)$ & $25(89)$ & $70(84)$ & $23(82)$ \\
\hline
\end{tabular}


It is notable that all of them claimed that they have knowledge and skill in CPR. Surprisingly only $83(74.8 \%)$ and 85 (76.6\%) have knowledge and 73 $(65.6 \%)$ and $81(73.1 \%)$ claim the necessary skills in advanced life support and trauma support. The final part, administered medicine, shows the number of staff with knowledge of administering medicine that is relevant to the disease is only 93 (83.4\%). A quite similar skill, administering medicine that is relevant to the disease, shows the lowest level of staff without the skill as only 23 (20.7\%) staff have the essential skill. The pre-hospital care staff perceived their knowledge and skills in surprising ways. Some items whereby staff thought they had skills but lacked knowledge raise serious issues. However, if the staff thought that they had knowledge but not skills this might be because of their limited chances to practice the skills. Overall, the finding suggested that all the pre-hospital care personnel have basic life support knowledge and skills.

Nevertheless, the quantitative data only covers elements of specific knowledge and skills. The qualitative information is needed to give an overall insight about the issues arising and the strategies required for RN/AMOs with regards to maintaining their competency. Some matters arise from the qualitative data these are categorized and described below. Ten categories emerged with regards to the competency of the staff issues and strategies.

The issues arise with regards to the competency of the personnel

\section{Inefficient performance of the staff}

This category it relates to the number of complaints that were received by the MECCs. Most of the complaints received were about the inefficient staff responses toward the needs in emergencies. Eventually the complaints highlighted delayed responses, but the descriptions dealt with staff responses towards providing care. The key informants describe such complaints as opportunities for them to reflect on and sort out problems straight away. The lessons learned do not relate only to the respective center; the information has to be shared with counterparts so that improvements in staff competency can take place.

Many people are not aware one of the reasons why we are not performing better at the scene because the public and family members pressure us and they simply complain to us and order us. Due to that I believe many of us are demotivated and for sure we cannot perform effectively. Sometimes soft skills and effective communication will not work in an emergency environment.

(Nurse T, FGD 2)

\section{Irresponsible attitude of the staff}

Indeed, handling manpower can be very challenging in the MECCs. Some of the staff are not fully responsible for the tasks given and some are too selective about the type of cases they deal with. This is based on preference and this leads to their performance being affected because of their inexperience and previous bad experiences.

For me knowledge and skill are two different things, knowledge is easy to gain but the skill is not easy to do without much practice, as a result some of us are not confident to manage unfamiliar cases alone outside thus some of them like to choose certain case.

(Nurse F, FGD 2)

Other issues about the staff attitude is generally that all the staff who are going for the ambulance call have a standard qualification or competency but because of past history or bad experiences they often refuse to go to a call and often look for changing their assignment too.

(Nurse R, FGD 1)

\section{Taking risks in managing care}

It has been noticed by emergency physicians that some staff take risks in managing patients at the scene without consulting the physician.

We have to understand the limitations that they face when providing care outside but it does not mean they can do anything based on their gut feelings. Certainly management needs direct medical direction for ensuring that the staff is protected if anything happens. On the other hand, there are cases where nothing is done to the patient; for example there may be a severe chest pain in an IHD case but no oxygen is given.

(Emergency Physician 3)

For some cases, especially by the seniors, some of them may not be keen about the medical direction and they try to decide things on their own. But slowly, they are getting there and find that medical direction is something which helps them and get them to do better rather than restrict them.

(Senior Head Nurse 2)

\section{Inefficient in completing run sheets}

Documentation issues are becoming a big concern in the EMS context. This is because care must continue from the scene to the hospital. The counterpart team in an emergency and trauma department really need to have baselines for their further management. Unfortunately, often they experience that the necessary run sheets are not completely filled in.

I know we are always having problems in filling the run sheets not because we don't know what to write but we are physically tired after getting back from the call and we thought that by verbally passing over at the ED it would be okay but they are now demanding us to fill in all details. Indeed it is very time consuming. (Nurse T, FGD 1)

Another thing is about their skill in putting information on the run sheet is not effective at all, it is always incomplete and lack important information. So many 
flaws can be observed and we hope to have a regular CME that could overcome this.

(Senior Head Nurse 2)

\section{Profession dilemma and misconduct}

As we are aware, EMS practice is extended use of emergency practices to provide services immediately outside the hospital context. In many countries paramedics are used mainly to deploy this service. This is unlike Malaysia where RN/AMOs have to take on this responsibility. However, they find certain aspects of clinical management are beyond their scope and in practice this creates a dilemma for them.

The nursing board has to play an important role on the does and don't for nurses who are involved in pre-hospital care. This is because there is often a contradiction between nursing board guidelines for the code of conduct and pre-hospital care guidelines. (Nurse T, FGD 1)

For example if we go for an ambulance call and the case is 'fitting' and the patient has a fit during arrival. In our guidelines of pre-hospital care Valium can be given. But in reality our code of conduct is not to give any drug without orders.

(Nurse A, FGD 1)

Strategies to facilitate the competency of the personnel

During the interview session the participants shared the events and challenges relating to their competency. They also offered some suggestions to institute practices at their and international levels whereby standards for current and future practice could be raised. The key informants identified strategies to bring about change. These included: staff centered approaches for in-house education programs; strengthening networking with other agencies; the need for mentoring staff and auditing their complete performance in providing pre-hospital care services; the need for consistent recertification; and motivating staff through awards and recognition.

Staff centered approaches for in-house education programs

Professional continuing education in Malaysia is mandatory for staff who wish to renew their annual practicing certificates. Therefore, each department or organization needs to develop their own ways and creativity to make in-house education meaningful and beneficial to their staff needs and preferences.

We as administrators have to give their own pace of learning and recently we allowed them to decide what they want to learn and what teaching approaches they prefer; we have many sorts of and varieties teaching style and recently we put in a confession slot for them to confess about their bad practices and how to overcome them.

(Senior Head Nurse 2)
Strengthen networking with other agencies

In the focus group discussions many members expressed their views about the need for networking with regional and outside agencies. This would allow the sharing of ideas and experiences relating to pre-hospital care. This would provide staff great experience and enable them to learn.

I think we need to have networking with our neighboring countries or other outside agencies to learn how they experience the EMS practice according their context. We will definitely have something new to discover.

(AMO M, FGD 2)

The need for mentoring and audit

One of the strategies identified is intended to ensure that each of the new or junior staff would have close links with an expert senior. This would be audited to ensure that the individual staff underwent the supervision.

Normally we were told to have two way audits. One from the pre-hospital document and in the second we follow them and find out how they perform from the beginning. I don't prefer to see the document because sometimes their competency is difficult to judge from the document. I personally prefer just to follow up and sit with them in the ambulance and see how they respond to the service and from this we can see their quality of care.

(Head AMO)

The need for consistent recertification

The nature of the EMS context means that many of the skills required have to be given credit. This is because we cannot always put doctors in charge of pre-hospital care. Some of the courses that have been taken are out of date and so recertification is required. This could ensure that the process of care delivery is made smoothly and carried out on at the scene.

They must undergo a series of the credentialing processes for certain skills and for running the system too. This is because our key pre-hospital staff are $100 \%$ nurses and AMOs who go through training scheduled for that purpose. That also includes basic training, and refresher courses for recertification like the BLS and ACLS. I guess it's already laid down at the supervisory level. Only then we can only maintain the skills that include updating. But it has to be consistent.

(Senior Emergency Physician)

Nursing board and the AMOs board have their own job descriptions but the nursing board is more open now; the present one is much better. They just permitted their nurses to work in accord with the EMS needs. Even our matron is quite open on this. What we can do is credential them. Once they have credentials, we take the responsibility for them.

(National Head of Emergency Physician) 
Award and recognition for the motivation

It is thought to be necessary to motivate the staff for them to become the best key personnel for the EMS in the country. This has recently led to awards being made and the giving of recognition for excellent service and outstanding performances. This is intended to help staff in the service to strive for excellence all the time.

We have this new game taking place now around the entire MECC operation in Klang Valley to have competition on how to manage patients in the prehospital setting. We create a scenario and make a form of simulation in the outside areas for seeing their management and response skills. I hope this can bring some improvement for the service. (National Head of Emergency Physician)

\section{DISCUSSION}

This study indicates that personnel in both MECCs in the Klang Valley pre-hospital system basically have the required essential knowledge and skills. This is because of the nature of their qualifications take longer when compared to paramedic programs. But, because of the different settings and matters beyond their control they face many problems in practicing care and their skills. This information was gathered through collecting qualitative data whereby they admitted the limitations of their practices on the scene. Similar findings have been discussed by Bigham and colleagues. ${ }^{19}$ There are many challenges and barriers facing personnel when making decisions at the scene; these may lead to delays in providing pre-hospital care.

Serious attention needs to be given to overcome these matters. Some of the strategies that emerged in the qualitative data are also in line with the some previous literature. This has highlighted that effective medical direction needs to take place at all the time to ensure that excellent outcomes can be achieved. On top of that, regular professional development programs need to be in place to allow staff to refine their knowledge and skills. ${ }^{17,18,29}$ A recent article mentioned that medical direction, both direct and indirect, and oversight have not been systematically established in seven Asian countries, including Malaysia. Such overall direction can lead to better execution of EMS systems in those that have not achieved global standards. One of the factors causing unsystematic medical direction is that EMS are organized at many different levels national, state and local - thus preventing nationwide standards. ${ }^{30,31}$

These findings indicate that the EMS personnel in both Klang Valley are still facing some barriers in providing advanced life support knowledge and skills. This is because, unlike basic life support and trauma care, all of them have limited certification. Yet only 82.45\% of the HKL MECC and $54.8 \%$ of the HSB MECC have advanced life support certificates. This raises the issue of lack of competence in invasive procedures and administering medication. Such issues are of paramount importance. Hubble and colleagues ${ }^{32}$ found that nearly $50 \%$ of their respondents did not have the ability to perform accurate and complete drug calculation. This is consistent with the practice when the EMS personnel have no advanced life support certification. Similar finding in another study suggest that knowledge and skill are two different entities. This leads to under performance if the skill learned had not been adequately practiced, even though those surveyed claimed to have adequate knowledge. ${ }^{33}$ Thus defects have to be overcome immediately because studies have shown major defects. For example, epinephrine has to be administered by pre-hospital personnel under medical direction, as this results in good patient outcomes by preventing anaphylaxis shock from insect stings. ${ }^{34}$ MECCs need to be creative in order to deal with the problems occurring in the field pertaining to the competency of the EMS personnel. Appropriate courses or programs must be provided to avoid mismanagement in the future.

\section{CONCLUSION}

The uniqueness of the pre-hospital EMS system worldwide is made up of providers of one or more levels of training and skills. Generally they are known as paramedics and the system has its own credentials and certificates at state level. Regardless of the qualifications and position of the personnel the proficiency is generally the same for the pre-hospital care context. Their roles in pre-hospital care is from basic up to advanced care. The findings suggest that Malaysian pre-hospital personnel basically have essential knowledge and skills because of the nature of their qualifications. But because of the different settings and factors beyond their control they face many problems in practicing their skills and care. This information was gathered as qualitative data that suggests they admit their practical limitations on the pre-hospital scene.

\section{Conflict of interest}

Non declared.

\section{ACKNOWLEDGEMENT}

We would like to express our deepest gratitude to Directors of Hospital Kuala Lumpur and Hospital Sungai Buloh, Heads of Emergency and Trauma Departments for both participating hospitals, Medical Emergency Coordination Centers of Kuala Lumpur and Sungai Buloh for providing us necessary assistance in carrying out this research. Our utmost sincere appreciation to Dr Sarah Sheikh Abdul Karim, all the nurses/assistant medical officers, the key informants for the interview and focus group discussion about giving us fullest cooperation without whom there would be no findings. We thank International Islamic University Malaysia (IIUM) for providing funding and financial assistance for this study and Ministry of Health $(\mathrm{MoH})$ Malaysia for granting us permission to embark on this research. 


\section{REFERENCES}

1. World Health Organization. Prehospital trauma care systems, 2005.

2. Beaglehole R. Neglected global epidemic: three growing threats. In: The World Health Report Shaping the future. Geneva: World Health Organization, 2003.

3. Anderson RJ, Taliaferro EH. Injury prevention and control. J Emerg Med 1998; 16:489-98.

4. Marson A, Thomson J. The influences of prehospital trauma care on traffic accident mortality. J Trauma 2001; 50:917-20.

5. Husum H, Gilbert M, Wisborg T, et al. Rural prehospital trauma systems improve trauma outcome in low-income countries: a prospective study from north Iraq and Cambodia. J Trauma 2003; 54:1188-96.

6. Al-Shaqsi S. Models of International Emergency Medical Service (EMS) Systems. Oman Med J 2010; 25:320-3.

7. Sayed MJE. Measuring quality in emergency medical services: a review of clinical performance indicators. Emerg Med Int 2012; 2012:1-7.

8. National Highway Transport Safety Administration. What is EMS? NHTSA 2011. Available at: http://www.ems.gov. Accessed July 11, 2011.

9. Sikka N, Margolis G. Understanding diversity among prehospital care delivery system around the world. Emerg Med Clin North Am 2005; 23:99114.

10. MacFarlane C, Benn CA. Evaluation of emergency medical services system: a classification to assist in determination of indicators. Em Med $\mathrm{J}$ 2003; 20:188-91.

11. Myers JB, Slovis CM, Eckstein $M$, et al. Evidenced-based performance measure for emergency medical services system: a model for expanded EMS benchmarking. Prehosp Emerg Care 2008; 12:141-51.

12. MingMa MH, ChienLu T, ShuinNg JC, et al. Evaluation of emergency medical dispatch in out-of-hospital cardiac arrest in Taipei. Resuscitation 2007; 73:236-45.

13. Moore L. Measuring quality and effectiveness of prehospital EMS. Prehosp Emerg Care 1999; 3:325-31.

14. Health Information and Quality Authority. Prehospital emergency care key performance indicators for emergency response times, October 2012 (version 1.1). Dublin: Health Information and Quality Authority, 2012.

15. National Highway Transport Safety Administration. State Emergency Medical Services Systems: A model. The National Association of State EMS Officials, US Department of Transportation, 2008.

16. National Academy of Sciences-National Research Council. Accident death and disability: The neglected disease of modern society. National Academy of Sciences, 1966.
17. National Highway Transport Safety Administrator. Emergency medical services agenda for the future. 1996. Available at: http://www.ems.gov/pdf/2010/EMSA gendaWeb_7-06-10.pdf. Accessed October 8, 2014.

18. Alonso-Serra H, Blanton D, O'Connor RE. Physician medical direction in EMS. Prehosp Emerg Care 1998; 2:153-7.

19. Bigham BL, Aufderheide TP, Davis DP, et al. Knowledge translation in emergency medical services: A qualitative survey of barriers to guidelines implementation. Resuscitation 2010; 81:836-40.

20. Jameel A, Rasheed A, Theophilus G, et al. Trauma patient outcome after prehopsital trauma life support program. J Trauma 1997; 42:1018-22.

21. Shah CHMS, Ismail IM, Mohsin SSJS. Ambulance response time and emergency medical dispatcher program: a study in Kelantan, Malaysia.

Southeast Asian J Trop Med Public Health 2008; 39:1150-1.

22. Heilicser B, Stocking C, Siegler M. Ethical dilemmas in emergency medical services: the perspectives of the emergency medical technician. Ann Emerg Med 1996; 27:239-43.

23. Donabedian A. The Quality of Care: how can it be assessed? JAMA 1988; 260:1743-8.

24. Creswell JW. Research design: Quantitative, qualitative and mixed method approaches. 3rd Ed. California: Sage Publication, 2009.

25. Creswell JW, Plano Clark V. Designing and conducting mixed methods research. 2nd Ed. California: Sage publication, 2007.

26. Giddings LS, Grant BM. Mixed methods research for the novice researcher. Contemp Nurse 2006; 23:3-11.

27. Lincoln YS, Guba EG. Naturalistic Inquiry. 1st Ed. California: Sage Publication, 1985.

28. Graneheim U, Lundman, B. Qualitative content analysis in nursing research: concepts, procedure and measures to achieve trustworthiness. Nurse Educ Today 2004; 24:105-21.

29. Studnek JR, Fernandez AR, Margolis GS, et al. Physician medical oversight in emergency medical service: Where are we? Prehosp Emerg Care 2009; 13:53-8.

30. Nielsen K, Mock C, Joshipura M, et al. Assessment of the status of pre-hospital care in 13 low-and middle income countries. Prehosp Emerg Care 2012; 16:381-9.

31. Shin SD, Ong MEH, Tanaka H, et al. Comparison of emergency medical services sytems across pan-Asian countries: A web based survey. Prehosp Emerg Care 2012; 16:477-96.

32. Hubble MW, Paschal KR, Sanders TA. Medication calculation skills of practicing paramedics. Prehosp Emerg Care 2000; 4:253-60. 
33. Michau R, Roberts S, Williams B, Boyle M. An investigation of theory practice gap in undergraduate paramedic education. BMC Med Educ 2009; 9:1-7.

34. Fortenberry MD, Laine J, Shalit M. Use of epinephrine for anaphylaxis by emergency medical technicians in a wilderness setting. Ann Emerg Med 1995; 25:785-7. 